\title{
Defining postoperative ileus and associated risk factors in patients undergoing radical cystectomy with an Enhanced Recovery After Surgery (ERAS) program
}

Connor M. Forbes ${ }^{1}$; Ali Cyrus Chehroudi ${ }^{1}$; Miles Mannas ${ }^{1}$; Andrea Bisaillon² ${ }^{2}$ Tracey Hong ${ }^{2}$; Alan So ${ }^{1}$; Kelly Mayson ${ }^{3}$; Peter C. Black ${ }^{1}$

${ }^{1}$ Department of Urologic Sciences, University of British Columbia, Vancouver, BC, Canada; ${ }^{2}$ Department of Surgical Services, University of British Columbia, Vancouver, BC, Canada; ${ }^{3}$ Department of Anesthesiology University of British Columbia, Vancouver, BC, Canada

Cite as: Can Urol Assoc J 2020 July 27; Epub ahead of print. http://dx.doi.org/10.5489/cuaj.6546

Published online July 27, 2020

$* * *$

\section{Abstract}

Introduction: Postoperative ileus (POI) is a common complication of radical cystectomy (RC), occurring in 1.6-23.5\% of cases. It is defined heterogeneously in the literature. POI increases hospital length of stay and postoperative morbidity. Factors such as age, epidural use, length of procedure, and blood loss may impact POI. In this study, we aimed to evaluate risk factors that contribute to POI in a cohort of patients managed with a comprehensive Enhanced Recovery After Surgery (ERAS) protocol.

Methods: A retrospective review of consecutive patients who underwent RC from March 2015 to December 2016 at Vancouver General Hospital was performed. POI was defined a priori as insertion of nasogastric tube for nausea or vomiting, or failure to advance to a solid diet by the seventh postoperative day. To illustrate heterogeneity in previous studies, we also evaluated POI using other previously reported definitions in the RC literature. The influence of potential risk factors for POI, including patient comorbidities, American Society of Anesthesiologists score, gender, age, prior abdominal surgery or radiation, length of operation, diversion type, extent of lymph node dissection, removal date of analgesic catheter, blood loss, and fluid administration volume was analyzed.

Results: Thirty-six (27\%) of 136 patients developed POI. Using other previously reported definitions for POI, the incidence ranged from $<1-51 \%$. Node positive status and age at surgery were associated with POI on univariate analysis but not multivariable analysis.

Conclusions: A large range of POI incidence was observed using previously published definitions of POI. We advocate for a standardized definition of POI when evaluating RC outcomes. POI occurs frequently even with a comprehensive ERAS protocol, suggesting that additional measures are needed to reduce the rate of POI. 


\section{Introduction}

Radical cystectomy $(\mathrm{RC})$ is a major undertaking for urologic patients and surgeons. This 3-8 hour operation ${ }^{1}$ has a major complication rate of $4.9-25.5 \%$ and a 90 -day mortality rate of $2.7 \%{ }^{2,3}$ Post-operative ileus (POI), the delayed return of bowel function after surgery, occurs at a rate of $1.6-23.5 \%$ in the $\mathrm{RC}$ population. ${ }^{4}$ This rate depends on the definition of POI, which is highly heterogeneous in the literature, making direct comparison across studies difficult. ${ }^{4,5} \mathrm{POI}$ is associated with increased length of stay, readmission, re-operation, and mortality. ${ }^{4,6}$ Preventing POI could potentially reduce the risk of downstream adverse events, so investigation of associated risk factors has potential major clinical implications.

Previously reported risk factors for ileus post cystectomy include elevated body mass index, and older age. ${ }^{4}$ Some other potential risk factors, including the use of neoadjuvant chemotherapy, were not found to be linked to POI after cystectomy. ${ }^{7}$ However, most reports on POI come from an era that precedes the implementation of formal enhanced recovery after surgery (ERAS) protocols. ERAS protocols are designed to reduce the risk of post-operative complications and to enhance patient quality of life in the peri-operative period. ${ }^{8,9}$ ERAS is based on a multidisciplinary approach to standardizing each element of patient care based on the best available evidence. ERAS protocols guide not only post-operative care, but also preoperative and intra-operative management.

An important focus of ERAS in the context of radical cystectomy is to prevent POI, which may predispose patients to other complications, increase length of hospital stay and reduce overall patient experience. For example, bowel edema has been hypothesized to contribute to POI, and goal-directed therapy to optimize intraoperative fluid resuscitation is considered an essential element of ERAS. ${ }^{10}$ Epidural anesthesia post-operatively is also thought to hasten return of bowel function post operatively compared to the use of systemic opioids. ${ }^{11}$ Rectus sheath catheters may increase POI in colorectal surgery, however data are limited. ${ }^{12}$ In this study we aimed to assess risk factors for ileus after RC in patients managed with a formal institutional ERAS protocol.

\section{Methods}

A retrospective review of charts and data was performed at our institution from March 2015 to December 2016. This included assessment of complications according to the National Surgical Quality Improvement Program (NSQIP), a nationally validated, outcomes-based program to improve quality of surgical care. The start date coincided with a change in the database used for NSQIP data. Ethics approval was obtained from the institutional review board for this study.

Patients were included if they had undergone a radical cystectomy for bladder cancer in this time period. Patients were excluded if they underwent cystectomy for other indications such as radiation cystitis. Robotic cystectomies were excluded because there were few of them and they were the initial cases in our institution's robotic cystectomy program. 
All patients were managed in the context of a comprehensive ERAS protocol that was launched in our hospital in October 2014 (see Figure S1). This protocol included extensive teaching of all health care providers involved in the patient journey from the time of surgical booking to time of hospital discharge after surgery. This protocol included a 39 point checklist, categorized into 9 domains (Safety, Fall Risk/Care Plan, Cognition, Assessment, Pain Management, Bowel/Bladder, Nutrition \& Hydration, Skin/Dressings/Drains, Functional Mobility, Teaching/Discharge Planning). Rigorous auditing of adherence to ERAS was conducted in near real-time (monthly) with secondary measures taken to address suboptimal adherence. Outcomes including length of hospital stay and rates of complications reported to NSQIP were reviewed quarterly by the multidisciplinary ERAS team.

In order to define POI as our primary endpoint, we reviewed the literature for previous definitions. Most of the literature focuses on POI after colorectal surgery. Based on the consensus of our multidisciplinary peri-operative care team (including nurses, anesthetists, general surgeons and urologists), we settled on an objective and broadly inclusive definition that incorporated elements from many of the published definitions. Ileus for the purposes of our study was defined as insertion of a nasogastric tube for nausea, abdominal distension, or vomiting, or failure to advance to a solid diet by the seventh post-operative day. ${ }^{2,4}$ This definition was selected prior to beginning data collection.

We applied 6 additional definitions of ileus previously reported in the cystectomy literature to our patient data. These definitions, which are representative of formal definitions used in the radical cystectomy complication literature, are indicated in Table $3 .{ }^{4}$ The incidence of ileus using each of these definitions was compared.

Demographic data were collected from patient records, including age at surgery, sex, American Society of Anesthesiologists (ASA) score, and history of abdominal surgery or radiation. Surgical variables, including type of urinary diversion, duration of surgery (from nursing record), blood loss (from anesthesia record), and pathologic stage were collected. Other peri-operative variables were also recorded, including volume of intravenous fluid received at 48 hours and 7 days post-operatively, and duration of use of rectus sheath or epidural catheter.

Statistical analysis consisted of initial univariate analysis. Fisher's exact test was used for categorical variables. Shapiro-Wilk testing was applied for normalcy of numeric variables, with t-testing used for normally distributed variables and Wilcoxon-rank testing used for nonnormally distributed variables. All variables with a p-value of $<0.2$ on univariate analysis underwent multivariable analysis.

\section{Results}

From March 2015 to December 2016, 136 patients underwent open radical cystectomy for bladder cancer at our institution. Thirty-six patients (27\%) developed POI according to our $a$ priori definition. 
The incidence of ileus was compared using multiple published definitions in the cystectomy literature (Table 3 ). Incidence ranged from $<1 \%(\mathrm{n}=1$ of 129$)$ to $51 \%(\mathrm{n}=51$ of 100$)$ for POI, depending on the definition used, with the denominator varying according to available data.

Pre-operative, operative and post-operative variables are summarized in Table 1. The mean age was 67 (range $36-90)$ at the time of surgery and $87 \%(n=115)$ of the patients were male. Patients with POI were older on average ( 72 vs $65, p<0.001$ ). There were no statistically significant differences in other baseline patient demographics, including comorbidities such as diabetes or inflammatory bowel disease, or preoperative estimated glomerular filtration rate (eGFR).

Most patients $(74 \%, \mathrm{n}=98)$ had an ileal conduit, and the mean operative time was 258 minutes (range 160-453 min). The standard pre-operative analgesia included epidural catheter. For part of the study period some patients were randomized to receive either an epidural catheter $(\mathrm{n}=75,57 \%)$ or a rectus sheath catheter $(\mathrm{n}=57,43 \%)$ in the context of a separate prospective randomized trial. Twenty-one patients had additional concurrent surgery at the time of cystectomy, including urethrectomy (4 patients), nephroureterectomy (4 patients), penectomy (2 patients), and umbilical hernia repair (2 patients). $\mathrm{T}$ stage, blood loss, or volume of fluids received perioperatively were not associated with POI.

The variables most strongly associated with POI (according to our definition) on univariable analysis were pathologic lymph node positivity $(\mathrm{p}=0.02)$ and older age at surgery $(\mathrm{p}<0.001)$. Older patients and those without lymph node metastases had higher rates of POI. Other variables with $\mathrm{p}<0.2$ were analgesic catheter type, previous radiation, other surgery performed concurrently, and pre-operative eGFR. When these variables were entered into a multivariable analysis using Wald's test, none remained statistically significant (Table 2). Age at surgery and pathologic $\mathrm{N}$ stage remained the closest to statistical significance, with $\mathrm{p}=0.09$ and $\mathrm{p}=0.07$ on multivariable analysis, respectively.

Appendix I summarizes available adherence data to representative ERAS checklist items at the time of two audits. From the 2014-2016 audit, which covers the study period, $\geq 80 \%$ adherence was observed in 7 of $12(58 \%)$ metrics analyzed. Interestingly, adherence was $<80 \%$ for the dietary and mobility metrics post-operatively, which might be expected to impact POI. A subsequent audit in 2019, after the study period, showed a slight improvement to $\geq 80 \%$ adherence in 15 of $23(65 \%)$ analyzed metrics.

\section{Discussion}

Post-operative ileus occurs frequently after abdominal surgery and has a major impact on the burden of health care costs. For example, in a retrospective cohort of 17,876 colorectal surgery cases in the United States, the incidence of POI was $17.4 \%$, and the mean additional cost was approximately $\$ 9,000$ USD for every patient with a POI. ${ }^{13}$ Enhanced Recovery after Surgery (ERAS) protocols have been launched widely in an effort to reduce the rate of POI, along with 
length of hospital stay and other measures of post-operative morbidity. ${ }^{14}$ There are 22 items defined in the ERAS Society guidelines for radical cystectomy, including individual parameters such as omitting pre-operative bowel preparation, use of epidural catheter, use of antibiotics, and administration of early oral fluids. ${ }^{15,16,17}$ Nonetheless, as our data demonstrate, POI remains common ( $27 \%$ of cases) even in the context of a formal, comprehensive ERAS protocol that has strong multidisciplinary institutional support with frequent rigorous auditing.

The definitions of ileus in the literature are variable. Previous studies of POI after radical cystectomy have used definitions based on the time to first flatus, bowel movement, or diet as tolerated (DAT), insertion of a nasogastric tube, or vomiting requiring cessation of oral intake. ${ }^{4}$ Interestingly, in a review of POI after cystectomy, 56 of the 77 included studies did not include a specified definition of ileus and relied instead on a clinical diagnosis. ${ }^{4} \mathrm{We}$ analyzed the studies that had a specific, reproducible definition of ileus and selected our outcome definition a priori before beginning data collection. Other representative definitions from the literature were also applied to our data to compare POI incidence. We found great variability in the incidence of POI depending on definition, ranging from $1 \%$ if defined by absence of flatus and bowel movement on the $6^{\text {th }}$ post-operative day, to $51 \%$ if defined by DAT on the $4^{\text {th }}$ post-operative day. The limitation of using first flatus, bowel movement or DAT in the definition of ileus is the potential for any one of these to be realized early in the post-operative course, but followed later by typical signs and symptoms of POI. For example, patients may be started empirically on a solid diet immediately after surgery only to require a nasogastric tube for nausea and vomiting days later. On the other hand, our definition relies in part on the subjective clinical decision to insert a nasogastric tube, which may be placed more or less liberally by different providers and at different centers. There has been difficulty finding a consensus definition for ileus, ${ }^{5}$ and it may not be appropriate to have the same definition for all surgeries. However, this study helps to illustrate the large variability in POI incidence depending on definition used.

We have analyzed the risk factors for POI in a cystectomy population managed with an ERAS protocol. The two factors predictive of POI on univariate analysis were age at surgery and pathologic nodal involvement ( $<<0.001$ and $p=0.02$, respectively). However, neither of these remained statistically significant on multivariable analysis. Mean age was 72 for those patients who developed POI, compared to 65 for those patients who did not develop POI. Previous studies have found an association between age and POI after radical cystectomy. ${ }^{7}$ The reason for this observed age-dependence of POI is unknown, but proposed mechanisms include decreased mobility, decreased tolerance for the side effects of opioid medications, and decreased motility of the bowels at baseline. ${ }^{7}$

The absence of nodal metastasis (pN0 vs. pN1-3) was statistically significant for association with POI on univariate analysis $(\mathrm{p}=0.02)$, but did not retain significance on multivarible analysis. This association would be difficult to explain, since one would postulate the opposite, whereby an increase in severity of disease or a more extensive lymph node 
dissection might result in a higher rate of POI. In our study as well as in prior studies, the extent of lymph node dissection did not predict ileus. ${ }^{18,19}$ A recent randomized controlled trial from Germany found no difference in recurrence-free or overall survival with an extended lymph node dissection compared to a limited lymph node dissection. ${ }^{20}$ Of note in that study, ileus incidence (which was not explicitly defined) was comparable between groups. POI occurred in 22 of 190 $(12 \%)$ limited lymph node dissection patients and 14 of $173(8 \%)$ extended lymph node dissection patients.

The mean time to removal of epidural or rectus sheath catheters for patients who developed POI was 3.8 days compared to 3.4 days for the non-POI patients $(\mathrm{p}=0.3)$. The occurrence of POI could itself affect duration of use of an analgesic catheter, so that we cannot conclude that a longer duration of indwelling analgesic catheter causes POI. In a Cochrane review, patients with epidural catheters have been found to have reduced time to return of normal gastrointestinal function, duration of hospital stay, and pain after abdominal surgery compared to patients without epidural catheters. ${ }^{21}$ A small study comparing rectus sheath to epidural catheter for return of bowel function did find a statistically significantly higher incidence in ileus in the rectus sheath group, but the absolute numbers were too small to be widely generalizable. ${ }^{14}$ Our study did not find an association between type of analgesic catheter and incidence of POI.

A noteworthy negative finding is that intravenous fluid administration, both intraoperatively and in the first 48 hours, was not associated with ileus. A small randomized controlled trial found that time to postoperative return of bowel function was reduced with restricted intravenous fluid and salt administration. ${ }^{22}$ The authors hypothesized that reduced gastrointestinal edema could explain this finding. Another randomized study found that a restrictive intraoperative hydration protocol coupled with a norepinephrine infusion resulted in a lower complication rate and a shorter hospital stay. ${ }^{23}$ However, shortened hospital stay was not replicated in a different study in colorectal patients ${ }^{24}$, and our study also did not find an association. Our series may lack the power to discern differences based on fluid volumes, especially since all patients were managed with the intent of restricting fluids despite differences in volume.

Previous radiation and concurrent performance of another surgery at the time of cystectomy were not associated with POI in this study. Radiation might be suspected to have an association with ileus by obliteration of surgical planes and reduced tissue healing. However, complication rates, including ileus, have not been found to have an association with radiation in a study including 846 patients. ${ }^{25}$ Likewise, the performance of another surgery at the time of cystectomy increases OR time and potentially increases bowel manipulation, but was not found to have an association with ileus for our study. This is possibly because the types of additional surgery were often not intraabdominal (eg penectomy, urethrectomy) and therefore might have only a minor impact on bowel function. 
An important conclusion of our study is that we need to continue to identify new means to reduce the rate of POI after cystectomy, and thereby improve patient outcomes. Alvimopan and $\mathrm{N}$-methylnaltrexone are peripheral mu-opioid receptor antagonists, that represent an important advance in peri-operative care. ${ }^{26}$ The evidence for $\mathrm{N}$-methylnaltrexone in the setting of radical cystectomy is very limited, ${ }^{27}$ but one multi-institutional randomized controlled trial has evaluated the impact of alvimopan on the return of bowel function after cystectomy in 277 patients managed without a formal ERAS protocol. ${ }^{26,28}$ Those patients who received alvimopan for 7 days postoperatively had statistically significantly reduced need for nasogastric tube insertion post operatively ( $24.6 \%$ vs $7.7 \%$, $\mathrm{p}<0.001) .{ }^{26}$ Although the definition differs between studies, the non-alvimopan group had a similar incidence of nasogastric tube insertion as POI in our study, while the alvimopan group was greatly improved. There were also significant improvements in time to solid food intake, length of stay, major adverse events, and POI-related morbidity. ${ }^{26}$ This was designated as moderate-quality evidence supporting alivimopan's use for radical cystectomy. ${ }^{28}$ It is important to emphasize, however, that these patients were not managed with a formal ERAS protocol, so it remains uncertain whether alvimopan would have the same impact in an ERAS cohort. Alvimopan has not been approved in Canada and was not available for use in our patient cohort. ${ }^{29}$

This study has several limitations. Firstly, the study is observational in nature, which precludes randomization and reduces the level of evidence. The study was also at a single, tertiary academic centre. Local practice and referral patterns, which were not captured in our data and analysis, may limit the generalizability of the findings to other cystectomy populations. A multi-institutional approach would have yielded more generalizable results, and this is something to consider for future studies. The small sample size limits the power of the analysis, and it is possible that a greater number of patients would have resulted in statistical significance for one or more of the tested variables. In addition, greater numbers would have allowed for the use of advanced statistical techniques, such as propensity score matching, which can counteract confounders even in studies lacking a control group. Noteworthy strengths of the study include the prospective collection of most of the data including the adherence to individual components of the ERAS protocol, and the granularity of data available such as intra-operative fluid resuscitation. While this study did not include robotic approaches, future studies could also examine the impact of newer robotic approaches on POI after cystectomy in the Canadian population.

\section{Conclusions}

Post-operative ileus remains a common complication after radical cystectomy even when patients are managed with a comprehensive ERAS protocol. The incidence of POI after RC varies greatly depending on definition of POI used. Age and pathologic nodal involvement were found to be associated with POI in this retrospective review on univariate although not multivariable analysis. This may help to identify patients at higher risk for POI. More research 
needs to be conducted in order to further reduce the rate of POI after radical cystectomy in the setting of comprehensive ERAS. 


\section{References}

1. Parekh DJ, Reis IM, Castle EP, et al. Robot-assisted radical cystectomy verus open radical cystectomy in patients with bladder cancer (RAZOR): an open-label, randomised, phase 3, non-inferiority trial. Lancet 2018: 391:2525-36.

2. Lawrentschuk N, Colombo R, Hakenberg OW, et al. Prevention and management of complications following radical cystectomy for bladder cancer. Eur Urol 2010;57(6):983-1001.

3. Shabsigh A, Korets R, Vora KC, et al. Defining early morbidity of radical cystectomy for patients with bladder cancer using a standardized reporting methodology. Eur Urol 2009;55(1):164-74.

4. Ramirez JA, McIntosh AG, Strehlow R, et al. Definition, incidence, risk factors, and prevention of paralytic ileus following radical cystectomy: a systematic review. Eur Urol 2013;64(4):588-97.

5. Gero D, Gié O, Hübner M, et al. Postoperative ileus: in search of an international consensus on definition, diagnosis, and treatment. Langenbecks Arch Surg 2017; 402(1):149-58.

6. Tevis SE, Carchman EH, Foley EF, et al. Postoperative Ileus--More than Just Prolonged Length of Stay? J Gastrointest Surg Off J Soc Surg Aliment Tract 2015;19(9):1684-90.

7. Svatek RS, Fisher MB, Williams MB, et al. Age and body mass index are independent risk factors for the development of postoperative paralytic ileus after radical cystectomy. Urology 2010;76(6):1419-24.

8. Melnyk M, Casey RG, Black P, et al. Enhanced recovery after surgery (ERAS) protocols: Time to change practice? CUAJ 2011; 5(5):342-8.

9. Frees S, Aning JJ, Black PC, et al. A prospective randomized pilot study evaluating an ERAS protocol versus a standard protocol for patientsd treated with radical cystectomy and urinary diversion for bladder cancer. World J Urol 2017; 36:215-20.

10. Rollins KE, Lobo DN. Intraoperative Goal-directed Fluid Therapy in Elective Major Abdominal Surgery: A Meta-analysis of Randomized Controlled Trials. Ann Surg 2016;263(3):465-76.

11. Park HK, Kwak C, Byun SS, et al. Early removal of nasogastric tube after

1. cystectomy with urinary diversion: does post-operative ileus risk increase? Urology 2005; 65(5):905-8.

12. Parekh DJ, Gilbert WB, Koch MO, et al. Continent urinary reconstruction versus

2. ileal conduit: a contemporary single institution comparison of perioperative morbidity and mortality. Urology 2000; 55(6): 852-5.

13. Iyer S, Saunders WB, Stemkowski S. Economic burden of postoperative ileus associated with colectomy in the United States. J Manag Care Pharm 2009;15(6):485-94.

14. Godden AR, Marshall MJ, Grice AS, et al. Ultrasonography guided rectus sheath catheters versus epidural analgesia for open colorectal cancer surgery in a single centre. Ann R Coll Surg Engl 2013;95(8):591-4.

15. Semerjian A, Milbar N, Kates M, et al. Hospital Charges and Length of Stay Following Radical Cystectomy in the ERAS Era. Urology 2017;111:86-91. 
16. Charoenkwan K, Matovinovic E. Early versus delayed oral fluids and food for reducing complications after major abdominal gynaecologic surgery. Cochrane Database Syst Rev 2014;12:CD004508.

17. Cerantola Y, Valerio M, Persson B, et al. Guidelines for perioperative care after radical cystectomy for bladder cancer: Enhanced Recovery After Surgery (ERAS(®)) society recommendations. Clin Nutr Edinb Scotl 2013;32(6):879-87.

18. Brössner C, Pycha A, Toth A, et al. Does extended lymphadenectomy increase the morbidity of radical cystectomy? BJU Int 2004;93(1):64-6.

19. Leissner J, Ghoneim MA, Abol-Enein H, et al. Extended radical lymphadenectomy in patients with urothelial bladder cancer: results of a prospective multicenter study. $J$ Urol 2004;171(1):139-44.

20. Gschwend JE, Heck MM, Lehmann J, et al. Extended Versus Limited Lymph Node Dissection in Bladder Cancer Patients Undergoing Radical Cystectomy: Survival Results from a Prospective, Randomized Trial. Eur Urol 2019;75(4):604-11.

21. Guay J, Nishimori M, Kopp S. Epidural local anaesthetics versus opioid-based analgesic regimens for postoperative gastrointestinal paralysis, vomiting and pain after abdominal surgery. Cochrane Database Syst Rev 2016;7:CD001893.

22. Lobo DN, Bostock KA, Neal KR, et al. Effect of salt and water balance on recovery of gastrointestinal function after elective colonic resection: a randomised controlled trial. Lancet. 2002 25;359(9320):1812-8.

23. Wuethrich PY, Burkhard FC, Thalmann GN, et al. Restrictive deferred hydration combined with preemptive norepinephrine infusion during radical cystectomy reduces postoperative complications and hospitalization time: a randomized clinical trial. Anesthesiology 2014;120(2):365-77.

24. MacKay G, Fearon K, McConnachie A, et al. Randomized clinical trial of the effect of postoperative intravenous fluid restriction on recovery after elective colorectal surgery. Br J Surg 2006;93(12):1469-74.

25. Ramani VAC, Maddineni SB, Grey BR, et al. Differential complication rates following radical cystectomy in the irradiated and nonirradiated pelvis. Eur Urol 2010;57(6):105863.

26. Lee CT, Chang SS, Kamat AM, et al. Alvimopan accelerates Gastrointestinal recovery after

3. radical cystectomy: a multicenter randomized placebo-controlled trial. Eur Urol 2014; 66(2):265-72.

27. Lenis A, Golla V, Lec $\mathrm{P}$ et al. The association between N-methylnaltrexone, a peripherally acting mu-opioid receptor antagonist, and clinical outcomes in patients undergoing robotic-assisted radical cystectomy. World J Urol 2020; online ahead of print.

28. Sultan S, Coles B, Dahm P. Alvimopam for recovery of bowel function after radical cystectomy. Cochrane Database Syst Rev 2017:CD012111.

29. Government of Canada Drug and Health Project Register. Regulatory decision summary - alvimopan - Health Canada. Updated Apr 15, 2019. Accessed Apr 7, 2020. https://hprrps.hres.ca/reg-content/regulatory-decision-summarydetailTwo.php?lang=en\&linkID=RDS00231\&wbdisable=true 


\section{Figures and Tables}

Fig. 1. Number of patients diagnosed with post-operative ileus based on time to nasogastric tube (NGT) placement or failure to advance diet (patient not on a solid diet on postoperative day [POD] 7).

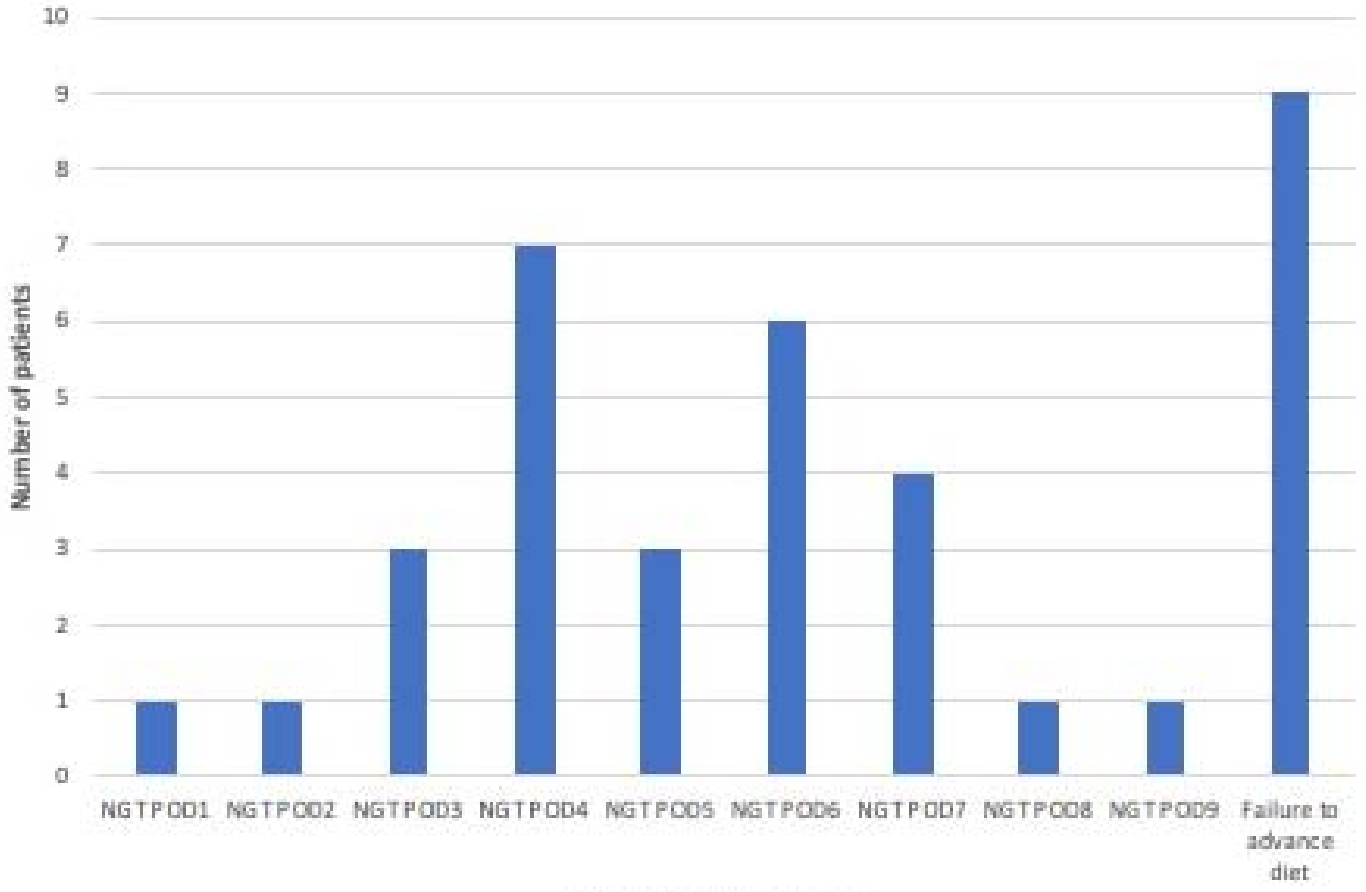

Reason for ileus diagnosis 


\begin{tabular}{|c|c|c|c|}
\hline Variable & Ileus & No ileus & $\mathbf{p}$ \\
\hline Total patients & $36(27 \%)$ & $97(73 \%)$ & N/A \\
\hline \multicolumn{4}{|l|}{ Pre-surgical factors } \\
\hline $\begin{array}{l}\text { Sex } \\
\text { Male } \\
\text { Female }\end{array}$ & $\begin{array}{c}30(83 \%) \\
6(17 \%)\end{array}$ & $\begin{array}{l}85(88 \%) \\
12(12 \%)\end{array}$ & 0.57 \\
\hline $\begin{array}{l}\text { Mean age at surgery } \\
\text { (range) }\end{array}$ & $72(49-86)$ & $65(36-90)$ & $<0.001^{*}$ \\
\hline $\begin{array}{l}\text { Diabetes } \\
\text { Yes } \\
\text { No } \\
\end{array}$ & $\begin{aligned} 7(5 \%) \\
29(22 \%) \\
\end{aligned}$ & $\begin{array}{l}15(11 \%) \\
82(62 \%) \\
\end{array}$ & 0.6 \\
\hline $\begin{array}{l}\text { Inflammatory bowel } \\
\text { disease } \\
\text { Yes, on treatment } \\
\text { Yes, no treatment } \\
\text { No }\end{array}$ & $\begin{array}{c}0 \\
3(8 \%) \\
33(92 \%)\end{array}$ & $\begin{array}{c}0 \\
5(5 \%) \\
92(95 \%)\end{array}$ & 0.45 \\
\hline $\begin{array}{l}\text { Previous abdominal } \\
\text { surgery } \\
\text { Yes } \\
\text { No } \\
\end{array}$ & $\begin{array}{l}11(31 \%) \\
25(69 \%) \\
\end{array}$ & $\begin{array}{l}32(33 \%) \\
64(67 \%) \\
\end{array}$ & 0.84 \\
\hline $\begin{array}{l}\text { Previous radiation } \\
\text { Yes } \\
\text { No }\end{array}$ & $\begin{array}{c}5(14 \%) \\
31(86 \%)\end{array}$ & $\begin{array}{c}5(5 \%) \\
91(95 \%)\end{array}$ & 0.14 \\
\hline $\begin{array}{l}\text { Neoadjuvant } \\
\text { chemotherapy } \\
\text { Yes } \\
\text { No }\end{array}$ & $\begin{array}{c}8(22 \%) \\
28(78 \%)\end{array}$ & $\begin{array}{l}31(32 \%) \\
65(68 \%)\end{array}$ & 0.29 \\
\hline $\begin{array}{l}\text { Mean Preoperative eGFR } \\
\left(\mathrm{ml} / \mathrm{min} / 1.73 \mathrm{~m}^{2} \text {, range }\right)\end{array}$ & $67(33-98)$ & $73(13-127)$ & 0.19 \\
\hline $\begin{array}{c}\text { ASA } \\
1 \\
2 \\
3 \\
4 \\
\end{array}$ & $\begin{array}{c}1(3 \%) \\
13(36 \%) \\
22(61 \%) \\
0(0 \%)\end{array}$ & $\begin{array}{c}3(3 \%) \\
48(52 \%) \\
40(43 \%) \\
2(2 \%)\end{array}$ & 0.27 \\
\hline \multicolumn{4}{|l|}{ Operative factors } \\
\hline $\begin{array}{l}\text { Mean operative time } \\
\text { (min, range) }\end{array}$ & $253(160-358)$ & $261(160-453)$ & 0.77 \\
\hline $\begin{array}{l}\text { Type urinary diversion } \\
\text { Ileal conduit } \\
\text { Studer neobladder }\end{array}$ & $\begin{array}{c}30(83 \%) \\
5(14 \%)\end{array}$ & $\begin{array}{l}68(70 \%) \\
24(25 \%)\end{array}$ & 0.42 \\
\hline
\end{tabular}




\begin{tabular}{|c|c|c|c|}
\hline $\begin{array}{l}\text { Indiana pouch } \\
\text { Other }\end{array}$ & $\begin{array}{c}1(3 \%) \\
0\end{array}$ & $\begin{array}{l}2(2 \%) \\
3(3 \%) \\
\end{array}$ & \\
\hline $\begin{array}{l}\text { Pelvic lymph node } \\
\text { dissection } \\
\text { None } \\
\text { Standard } \\
\text { Extended } \\
\end{array}$ & $\begin{array}{c}0(0 \%) \\
26(72 \%) \\
10(288 \%) \\
\end{array}$ & $\begin{array}{c}3(3 \%) \\
61(63 \%) \\
33(34 \%) \\
\end{array}$ & 0.56 \\
\hline $\begin{array}{l}\text { Other surgery performed } \\
\text { concurrently } \\
\text { Yes } \\
\text { No }\end{array}$ & $\begin{array}{c}3(8 \%) \\
33(92 \%)\end{array}$ & $\begin{array}{l}18(19 \%) \\
79(81 \%)\end{array}$ & 0.19 \\
\hline $\begin{array}{l}\text { Estimated blood loss } \\
>500 \mathrm{~mL} \\
\text { Yes } \\
\text { No } \\
\end{array}$ & $\begin{array}{l}18(51 \%) \\
17(49 \%) \\
\end{array}$ & $\begin{array}{l}48(53 \%) \\
42(47 \%) \\
\end{array}$ & \\
\hline $\begin{array}{l}\text { Estimated blood loss (ml, } \\
\text { range) }\end{array}$ & $747(200-2500)$ & $797(150-3000)$ & 1 \\
\hline $\begin{array}{l}\text { Intraoperative crystalloid } \\
\text { (mean mL, range) }\end{array}$ & $3044(1400-5400)$ & $3037(900-6000)$ & 0.9 \\
\hline $\begin{array}{l}\text { Analgesia catheter type } \\
\text { Epidural } \\
\text { Rectus sheath }\end{array}$ & $\begin{array}{l}24(67 \%) \\
12(33 \%)\end{array}$ & $\begin{array}{l}51(53 \%) \\
45(47 \%)\end{array}$ & 0.39 \\
\hline $\begin{array}{l}\text { Abdominal or pelvic } \\
\text { drain inserted } \\
\text { Yes } \\
\text { No } \\
\end{array}$ & $\begin{array}{c}34(94 \%) \\
2(6 \%)\end{array}$ & $\begin{array}{c}90(95 \%) \\
5(5 \%)\end{array}$ & 1 \\
\hline \multicolumn{4}{|l|}{ Postoperative factors } \\
\hline $\begin{array}{l}\text { Pathologic T stage } \\
\text { T0/Ta/Tis/T1 } \\
\text { T2/T3/T4 } \\
\end{array}$ & $\begin{array}{l}17(47 \%) \\
19(53 \%) \\
\end{array}$ & $\begin{array}{l}44(45 \%) \\
53(55 \%) \\
\end{array}$ & 0.85 \\
\hline $\begin{array}{l}\text { Pathologic N stage } \\
\text { N0 } \\
\text { N1/N2/N3 }\end{array}$ & $\begin{array}{c}32(89 \%) \\
4(11 \%)\end{array}$ & $\begin{array}{l}66(68 \%) \\
29(32 \%)\end{array}$ & 0.02 \\
\hline $\begin{array}{l}\text { Transfused in first } 48 \\
\text { hours } \\
\text { Yes } \\
\text { No }\end{array}$ & $\begin{array}{l}12(36 \%) \\
21(64 \%)\end{array}$ & $\begin{array}{l}25(28 \%) \\
65(72 \%)\end{array}$ & 0.38 \\
\hline $\begin{array}{l}\text { Mobilized once POD } 0-1 \\
\text { Yes } \\
\text { No }\end{array}$ & $\begin{array}{l}14(51 \%) \\
13(49 \%) \\
\end{array}$ & $\begin{array}{l}46(61 \%) \\
30(39 \%) \\
\end{array}$ & 0.5 \\
\hline $\begin{array}{l}\text { Full fluids started on } \\
\text { POD\#1 } \\
\text { Unrestricted } \\
\text { Restricted }(<500 \mathrm{ml}) \\
\end{array}$ & $\begin{array}{c}0 \\
20(57 \%) \\
\end{array}$ & $\begin{array}{c}6(6 \%) \\
63(66 \%) \\
\end{array}$ & 0.14 \\
\hline
\end{tabular}




\begin{tabular}{|l|c|c|c|}
\hline \multicolumn{1}{|c|}{ No } & $15(43 \%)$ & $27(28 \%)$ & \\
\hline Patient hypotensive on & & & \\
the ward (SBP <90) & $6(18 \%)$ & $12(13 \%)$ & 0.57 \\
$\quad$ Yes & $28(82 \%)$ & $82(87 \%)$ & 0.14 \\
$\quad$ No & $10121(6711-13932)$ & $9858(5888-$ & 0.3 \\
\hline First 48 hours fluid (mean & & $28973)$ & \\
mL, range) & $3.8(2-8)$ & $3.4(1-6)$ & \\
\hline Analgesic catheter & & \\
remove day postoperative & & & \\
(mean days, range) & & & \\
\hline
\end{tabular}

ASA: American Society of Anesthesiologists Score; eGFR: estimated glomerular filtration rate; POD: postoperative day; SBP: systolic blood pressure.

\begin{tabular}{|l|c|c|}
\hline $\begin{array}{l}\text { Table 2. Multivariable analysis for variables associated with postoperative ileus with } \\
\text { p }>\mathbf{0 . 2} \text { on univariate analysis }\end{array}$ & Reference variable & p \\
\hline Variable & ref = epidural & 0.15 \\
\hline Analgesic catheter type & ref = no \\
\hline Previous radiation & ref = N0 & 0.46 \\
\hline Pathologic N stage & ref = no \\
\hline $\begin{array}{l}\text { Other surgery performed } \\
\text { concurrently }\end{array}$ & & 0.07 \\
\hline Age at surgery & N/A & 0.2 \\
\hline Preoperative eGFR & N/A & 0.09 \\
\hline Fluid in the first 48 hours & N/A & 0.56 \\
\hline
\end{tabular}

eGFR: estimated glomerular filtration rate. 


\begin{tabular}{|l|c|c|c|}
\hline Table 3. Incidence of postoperative ileus (POI) by definition of ileus used \\
\hline Definition & $\begin{array}{c}\text { Number of } \\
\text { patients fulfilling } \\
\text { definition }\end{array}$ & $\begin{array}{c}\text { Number of } \\
\text { patients with } \\
\text { available data }\end{array}$ & $\begin{array}{c}\text { Percentage } \\
\text { of patients } \\
\text { with POI }\end{array}$ \\
\hline $\begin{array}{l}\text { NGT placement for } \\
\text { nausea/vomiting, or } \\
\text { inability to tolerate full diet on } \\
\text { POD 7 }\end{array}$ & 36 & 133 & $27 \%$ \\
\hline $\begin{array}{l}\text { NGT inserted for } \\
\text { nausea/vomiting/distension }\end{array}$ & 27 & 133 & $20 \%$ \\
\hline No BM or flatus on POD 6 & & & $1 \%$ \\
\hline No BM on POD 6 & 1 & 129 & $6 \%$ \\
\hline No BM on POD 4 & 8 & 126 & $38 \%$ \\
\hline $\begin{array}{l}\text { Inability to tolerate DAT on } \\
\text { POD7 }\end{array}$ & 33 & 126 & $24 \%$ \\
\hline $\begin{array}{l}\text { Inability to tolerate DAT on } \\
\text { POD 5 }\end{array}$ & 51 & 135 & $51 \%$ \\
\hline
\end{tabular}

*A priori definition used in this study. BM: bowel movement; DAT: diet as tolerated. NGT: nasogastric tube; POD: postoperative day. 
Appendix. Enhanced Recovery After Surgery (ERAS) protocol items and adherence

Supplementary Fig. 1. Key components of Enhanced Recovery After Surgery (ERAS) pathway utilized at our institution for radical cystectomy.

\begin{tabular}{|c|c|c|}
\hline \multicolumn{3}{|c|}{ Active Patient Involvement } \\
\hline Pre-operative & Intra-operative & Post-operative \\
\hline -Pre-admission education & -Active warming & - Early oral nutrition \\
\hline -Early discharge planning & -Opioid-sparing technique & -Early ambulation \\
\hline - Reduced fasting duration & -Surgical techniques & -Early catheter removal \\
\hline -Carbohydrate loading & \multirow{2}{*}{$\begin{array}{l}\text {-Avoidance of prophylactic } \\
\text { NG tubes \& drains }\end{array}$} & -Use of chewing gum \\
\hline - No/selective bowel prep & & -Defined discharge criteria \\
\hline $\begin{array}{l}\text {-Venous thromboembolism } \\
\text { prophylaxis }\end{array}$ & \multicolumn{2}{|c|}{-Pain \& nausea management } \\
\hline -Antibiotic prophylaxis & \multirow{2}{*}{\multicolumn{2}{|c|}{-Goal directed peri-operative fluid management }} \\
\hline -Pre-warming & & \\
\hline \multicolumn{3}{|c|}{ Audit of compliance \& outcomes } \\
\hline \multicolumn{3}{|c|}{ Whole Team Involvement } \\
\hline
\end{tabular}


Supplementary Fig. 2. Adherence to 12 key Enhanced Recovery After Surgery (ERAS) pathway components post-radical cystectomy from October 2014 to September 2016 ( $\mathrm{n}=152)$. POD: postoperative day.

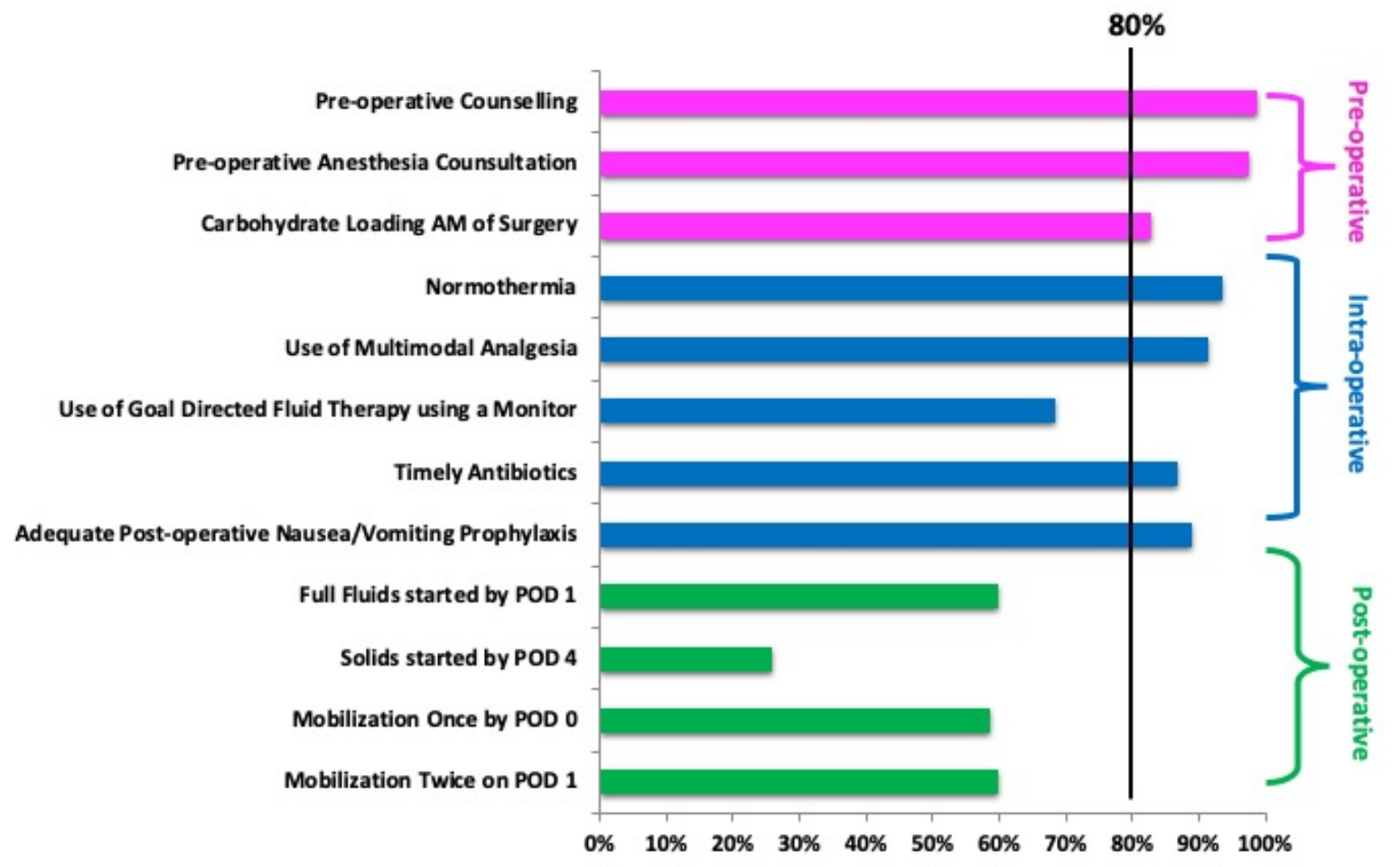

